\title{
Numerical Study on Response Characteristics of Solid Rocket Pintle Motor
}

\author{
Jeevan Sapkota¹, Yi Hua Xu1,*, Hai Jun Sun
}

\author{
Sapkota J (D) https://orcid.org/0000-0002-6165-2964 \\ Xu YH (D) https://orcid.org/0000-0002-4474-2300 \\ Sun HJ (D) https://orcid.org/0000-0003-4541-6758
}

How to cite

Sapkota J; Xu Y; Sun H (2019) Numerical Study on Response Characteristics of Solid Rocket Pintle Motor. J Aerosp Technol Manag, 11: e3419. https://doi.org/10.5028/jatm.v11.1050

\begin{abstract}
Pintle technology is currently a versatile technology used in a solid rocket motor (SRM) to control the desired thrust by changing the nozzle throat area, while effectively controlling the chamber pressure at the same time. The sudden movement of the pintle can induce rapid changes in the flow field and the occurrence of pressure oscillations inside the combustion chamber. The analysis of such rapid changes is essential to design an efficient controllable pintle rocket motor for a better thrust regulation. Two-dimensional axisymmetric models with mesh generation and required boundary condition were designed to analyze the effects of three different pintle head shape models in SRM thrust regulation effect. Dynamic mesh method was used with specific velocity for moving plug/pintle in the numerical analysis of SRM thrust regulation. The effects of different pintle head models on the flow field, combustion chamber pressure, mass-flow rate, thrust and Mach number were investigated. According to the analysis of total pressure response time, the simulation data revealed that circular pintle head model responded faster among three different models. According to the thrust effect, parabolic pintle has the maximum value of thrust and the greatest total pressure recovery coefficient among all pintle head models.
\end{abstract}

KEYWORDS: SRM, Pintle, Thrust regulation, Response characteristic.

\section{INTRODUCTION}

Solid rockets have less movable parts, reasonably good mass fraction and reasonable specific impulse, thus making them outstanding in comparison with other propellant rockets. Due to its simplicity and reliability, which has dominated the tactical missile field with no significant design compromises, it is also used in a larger application for low orbit satellite launch in form of boosters, air-to-air, air-to-ground military missiles and as model rockets (Ostrander et al. 2000).

The designed thrust profile of solid propellant motor is difficult to adjust once the solid propellant grains get ignited inside the chamber case. It burns continuously and unstoppably due to the presence of all the essential substance needed for the combustion inside the combustion chamber. A tapered plug, known as pintle, is introduced as a mechanism that directly controls the nozzle throat area and the nozzle thrust (Burroughs 2001; and Bergmans and Salvo 2003) (Fig. 1). The pintle can control the nozzle throat area and thrust when inserted towards the nozzle throat of SRM (Davis and Gerards 2003). A desired thrust can be achieved by changing the throat area while effectively controlling the chamber pressure at the same time. Although this technology has the advantages of throttling thrust and maintaining inherent advantages of the solid rocket motor, the sudden movement of the pintle can induce rapid changes of the flow field, pressure oscillations inside the combustion chamber, shock trains and flow separation in the nozzle and so on (Lee 2012; and Heo et al. 2013).

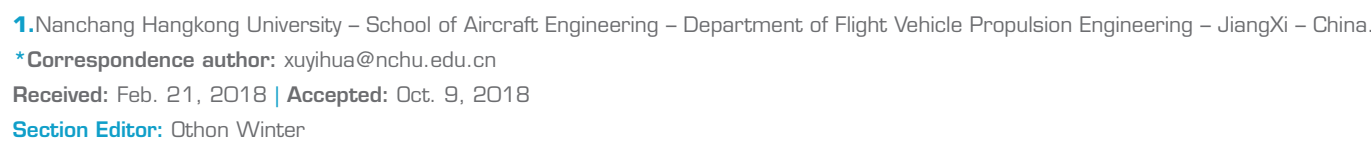


Many studies have been carried out in pintle technology from dual-thrust technology to control the burning surface of the solid propellant by designing the grain shape to increase mission range and end-game maneuverability (Dahl and Jones 1996) to fully controllable propulsion, suiting the circumstances of each emergency in escape system of military aircraft (Rock et al. 1997). In pintle technology the effects of several important parameters were studied, the relationship between the pintle geometry, pintle position and throat area were determined and used for design decisions (Ostrander et al. 2000). In terms of the pintle speed and geometries, performance variations were examined (Lee et al. 2013). Based on the Navier-Stokes equations described by Arbitrary Lagrangian-Eulerian (ALE), Li et al. (2009) analyzed the effects of the pintle moving velocity and free volume of motor on the controlling thrust capability with numerical simulation methods. Thus, the authors investigated the unsteady internal flow field during the thrust control process of pintle controlled SRM and the performance of pintle controlled thrust solid rocket motor. To develop a lightweight exoatmospheric projectile, Coon and Yasuhara (1993) researched theoretically and experimentally estimated chamber pressure and thrust versus changes in nozzle throat area. Nevertheless, in-depth or integrated fundamentals knowledge of the pintle-perturbed nozzle flow is very limited in the open literature. Moreover, few numerical analyses have been carried out with the use of dynamic mesh method in pintle nozzle.

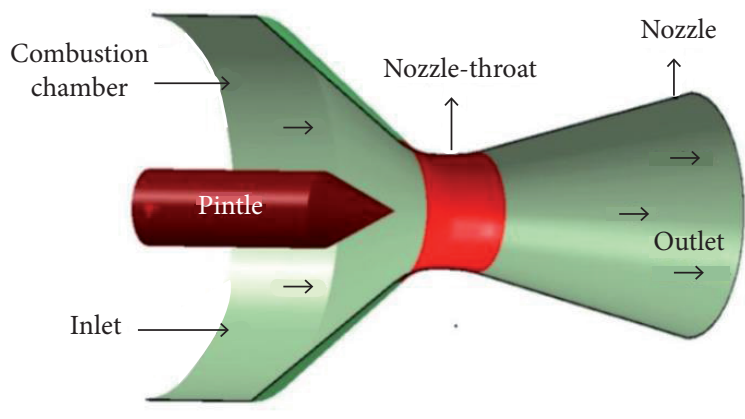

Figure 1. Schematic of pintle nozzle.

In this research, computational fluid dynamics (CFD) based study has been conducted to analyze the characteristics of thrust regulation effect with three different pintle head models. Different pintle head models on various positions were numerically examined to investigate its effects on thrust regulation, pressure, mass-flow rate and Mach number. Axisymmetric flow is simulated with dynamic mesh method of FLUENT by writing proper User Define Function (UDF) to simulate the pintle movement with specific velocity of $0.2 \mathrm{~m} / \mathrm{s}$.

\section{NUMERICAL METHODS}

This research numerical method solves a set of governing equations describing the conservation of mass, momentum (NavierStokes equations), energy, and turbulence quantities. These equations can be used with approximations based on knowledge of the properties of flow turbulence to give approximate time-averaged solutions to the Navier-Stokes equations the governing equations are written as (Eqs. 1 and 2):

$$
\begin{gathered}
\frac{\partial \rho}{\partial t}+\frac{\partial}{\partial x_{j}}\left(\rho u_{j}\right)=0 \\
\frac{\partial}{\partial t}\left(\rho u_{i}\right)+\frac{\partial}{\partial x_{j}}\left(\rho u_{i} u_{j}\right)=-\frac{\partial p}{\partial x_{i}}+\frac{\partial \tau_{i j}}{\partial x_{j}}
\end{gathered}
$$


where (Eq. 3):

$$
\tau_{i j}=\mu\left(\frac{\partial u_{i}}{\partial x_{j}}+\frac{\partial u_{j}}{\partial x_{i}}\right)-\frac{2}{3} \mu \frac{\partial u_{k}}{\partial x_{k}} \delta_{i j}, \quad \delta_{i j}= \begin{cases}1, & j=i \\ 0, & j \neq i\end{cases}
$$

For the momentum equation (here, the gravitational force is ignored), $p$ is pressure; $\rho$ is the fluid density; $u_{i}$ and $u_{j}$ represent the components of velocity vector; $x_{i}$ and $x_{j}$ represent the components of position vector; $\tau_{i j}$ is the viscous stress tensor; $\mu$ is the coefficient of viscosity; and $\delta_{i j}$ is the Kronecker delta function.

State equation (Eq. 4):

$$
p=\rho R T
$$

Energy equation (Eq. 5):

$$
\frac{\partial}{\partial t}(\rho T)+\frac{\partial}{\partial x_{j}}\left(\rho u_{j} T\right)=\operatorname{div}\left(\frac{\lambda}{C_{p}} \operatorname{grad} T\right)+S_{T}
$$

where $R$ is the gas constant $8.314 \mathrm{~J} /(\mathrm{mol} \mathrm{K}) ; c_{p}$ is the specific heat at constant pressure; $T$ is temperature; $\lambda$ is coefficient of heat conduction; and $S_{T}$ is energy source.

The two-equation eddy-viscosity turbulence model of k- $\omega$ SST (Shear Stress Transport) were used and the implicit formulation was applied with Green Gauss cell based gradient option in the pressure-based solver. The spatial discretization employed a secondorder upwind differencing scheme in generalized coordinates.

\section{MODEL DESCRIPTION AND BOUNDARY CONDITION \\ MODEL DESCRIPTION}

Three different pintle head models of circular, conical and parabolic shape were studied for numerical research, illustrated in Fig. 2.

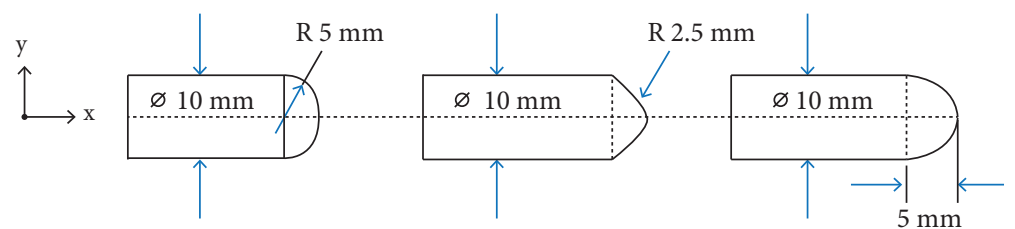

Figure 2. Three different pintle head models.

The typical nozzle design used in this numerical experiment is a conical nozzle with a straight-cut throat, an example is shown in Fig. 3. The conical nozzle typically has a convergence half angle of $\beta=\left(30^{\circ}-45^{\circ}\right)$ for reduced convergent section length. If $\beta$ value is too small, then it will increase the length of the convergence section and increase the mass and heat loss. If $\beta$ value is too large, then throat necking will happen, causing the loss of the flow and aggravating ablation. Usually, $\beta=45^{\circ}$ is taken for proper design of non-submerged convergence nozzle section. The optimal divergence half angle $\alpha=15^{\circ}$ results in a good compromise of minimizing the divergence losses without excessive nozzle length and weight. The nozzle throat radius $R_{\mathrm{t}}$ equals to $10 \mathrm{~mm}$, the width of the nozzle throat cylindrical section is $L \leq 0.5 R_{\mathrm{t}}$ (Fig. 3). The domain is extended from $(-105 \mathrm{~mm},+65.32 \mathrm{~mm})$ in $\mathrm{x}$-coordinate $(0 \mathrm{~mm}, 125 \mathrm{~mm})$ and in y-coordinate in all models. Structure and unstructured grid had been used due to the complex structure of the nozzle. 


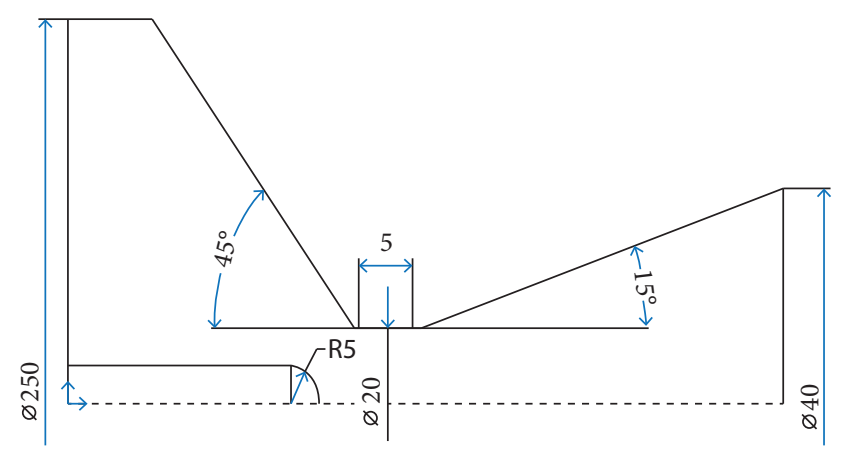

Figure 3. Conical nozzle with straight-cut throat parameters.

\section{BOUNDARY CONDITION}

Schematic of the pintle nozzle and boundary conditions is shown in Fig. 4. Several boundary conditions were applied in this research: the mass flow rate for the inlet boundary condition, pressure outlet boundary conditions for the subsonic flow, switched to extrapolation for the supersonic flow, no-slip adiabatic wall boundary condition on the nozzle and in the pintle wall. The axisymmetric boundary condition was specified along the nozzle axis. Dynamic mesh method has been applied to investigate the different pintle models movement effects on the thrust regulation.

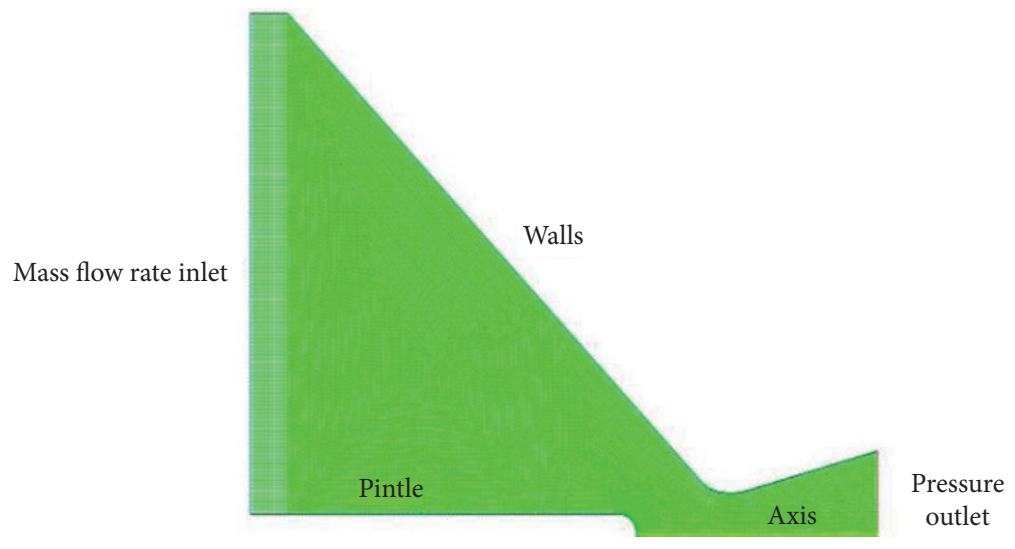

Figure 4. Applied boundary conditions.

The mass flow per unit area at the entrance of the nozzle is given in this paper. When the pintle starts to move towards the nozzle throat, nozzle throat area will decrease, resulting in increase of combustion chamber pressure, which also increases the mass-flow rate. So, the designed two-dimensional model of SRM entrance is defined as an inlet of an adaptive mass-flow rate and pressure. Through the calculation process, the pressure of the combustion chamber is read inside the engine and inlet mass flow rate is automatically adjusted to satisfy the law of burning rate change of propellant. The mass flow rate $(\dot{m})$ is obtained by Eq. 6 :

$$
\dot{m}=a p_{c}^{n} r_{p} A_{b}
$$

where $p_{c}$ is the equilibrium pressure of the combustion chamber; $\alpha$ is the combustion coefficient; $n$ is the pressure exponent; $\rho_{p}$ is the propellant density; and $A_{b}$ is the combustion surface area. 
The calculated equilibrium pressure is required to input as gauge total pressure. We can calculate the equilibrium pressure of the solid rocket motor combustion chamber with Eq. 7:

$$
p_{c}=\left(\rho_{p} C^{*} a K\right)^{\frac{1}{1-n}}
$$

where $C^{*}$ is the characteristic velocity; $a$ is the burn rate coefficient; and $n$ is the pressure exponent. The values of $a$ and $n$ are determined empirically for a particular propellant formulation and cannot be theoretically predicted. $K$ is the ratio between the burning surface area $\left(A_{b}\right)$ and nozzle throat area $\left(A_{t}\right)$, which are given by Eqs. 8 and 9.

$$
\begin{gathered}
A_{b}=\frac{p}{4}\left(D^{2}-d^{2}\right) ; \quad A_{t}=\frac{p}{4} d_{t}^{2} \\
K=\frac{A_{b}}{A_{t}}
\end{gathered}
$$

where $A_{b}$ is the area of the combustion surface; $D$ is the diameter of combustion surface; $d$ is the diameter of the pintle; and $d_{t}$ is the diameter of nozzle throat.

\section{RESULTS AND DISCUSSION}

The numerical simulation analysis has been carried out on the basis of the total pressure, mass-flow rate, total thrust and Mach number. The flow field has been simulated in $k$ - $\omega$ SST (Shear Stress Transport) two-equation eddy-viscosity turbulent model with three different pintle-head models. The factors that do not influence the principal law of the fluid motion were ignored. The fluid is Newtonian and gravity effects are neglected. Ideal gas is considered as the working fluid. Since the air velocity is always subsonic inside the chamber and convergent section of the nozzle, the outlet pressure is determined by the ambient pressure, velocity and density extrapolation. When the air velocity is supersonic all the parameters are determined by extrapolation. The flow field is about the central axis of the throat structure and only half of the flow field of the two-dimensional structure is calculated in axisymmetric mode. The simulation analysis of three different pintle head models has been based on their performance of total pressure, Mach number, total mass-flow rate and total thrust.

\section{TOTAL PRESSURE}

Figure 5 illustrates the achieved simulation data of inlet total pressure of three different pintle head models. All the models have a minimum value of total pressure while the pintles move from its initial position with the velocity of $0.2 \mathrm{~m} / \mathrm{s}$ to the front edge of the nozzle throat. Then this value is increased when the pintle started to enter the nozzle throat from the flow time of $0.10 \mathrm{~s}$. As we can see, the total pressure rapidly increased after the flow time duration of $0.10 \mathrm{~s}$ when pintle entered the nozzle throat. Afterward the pressure gradually increased to the maximum value of $10.75 \mathrm{MPa}$ till the flow time of $0.23 \mathrm{~s}$ in all the models, when pintle reached to the expansion section of the nozzle. As the pintle began to reciprocate towards its initial position from the expansion section of the nozzle, the total pressure rapidly starts to decrease after the flow time of $0.25 \mathrm{~s}$.

From this, we can analyze that the changes in the area of nozzle throat by the pintle has caused the sudden high spike of pressure changes inside the combustion chamber. It has been observed that among three different models, the circular pintle head model responded faster. Hence, different pintle head shapes have different impacts on the sudden rise and fall of total pressure inside the combustion chamber. 
(a)

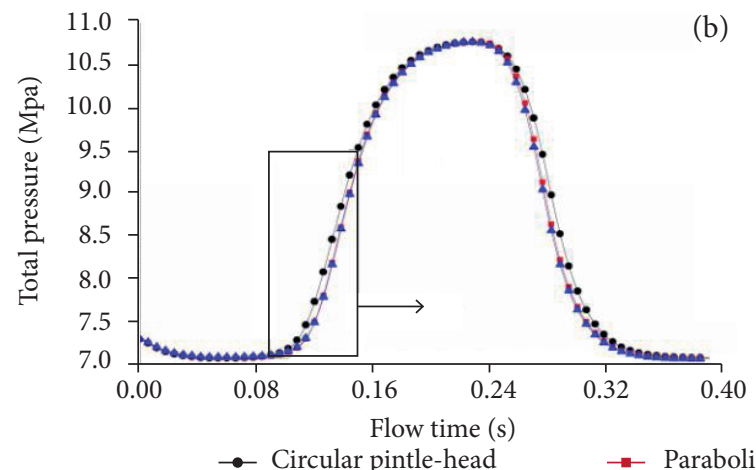

Figure 5. (a) Total pressure simulation data of three pintle head models; (b) Magnified display from the flow of 0.09-0.15s.

\section{TOTAL PRESSURE RECOVERY EFFICIENCY COEFFICIENT}

The total pressure recovery factor/coefficient is the ratio of the actual stagnation pressure at the outlet to the stagnation pressure at inlet of the nozzle. Thus the total pressure ratio can be written as (Eq. 10)

$$
s=\frac{p_{02}}{p_{01}}
$$

In the equation $P_{01}$ is the total pressure at inlet nozzle, which is same as the total pressure at exit, if the flow is isentropic. Due to the increase in entropy in the flow passage, the final stagnation pressure has changed to $P_{02}$. The total pressure recovery coefficient $(\sigma)$ of three different pintle head model is illustrated in Fig. 6. The $\sigma$ values for three different pintle models were calculated from the obtained inlet and outlet total pressure in the different flow time of pintle inserting toward the nozzle and reciprocating to its beginning initial stage, which has represented in sequences from the time duration of $0 \mathrm{~s}, 0.05 \mathrm{~s}, 0.1 \mathrm{~s}, 0.15 \mathrm{~s}, 0.2 \mathrm{~s}, 0.25 \mathrm{~s}$, $0.3 \mathrm{~s}, 0.35 \mathrm{~s}, 0.4 \mathrm{~s}$ in the chart. The obtained total pressure recovery coefficient value shows that circular pintle head model has the minimum value in comparison with two other pintle head, and parabolic pintle model has the maximum value. Comparing Figs. 5 and 6, it can be found that total pressure recovery coefficient decreases with the increasing amount of total pressure. Conversely, it increases as total pressure decreases. Due to the changes in the nozzle throat area by the pintle, total pressure increased rapidly during the flow time duration of 0.10-0.2 s when the pintle started to enter the nozzle throat, achieving the maximum value when the pintle reached to the nozzle outlet. Afterward it rapidly decreased while the pintle reciprocated towards its initial position (Fig. 5). The total pressure recovery coefficient value is maximum when the pintle is inside the combustion surface area and minimum during the flow time duration of 0.10-0.2 s, when the pintle enters the nozzle throat area and reaches to the nozzle, and gradually increased afterward as reciprocating toward its initial position.

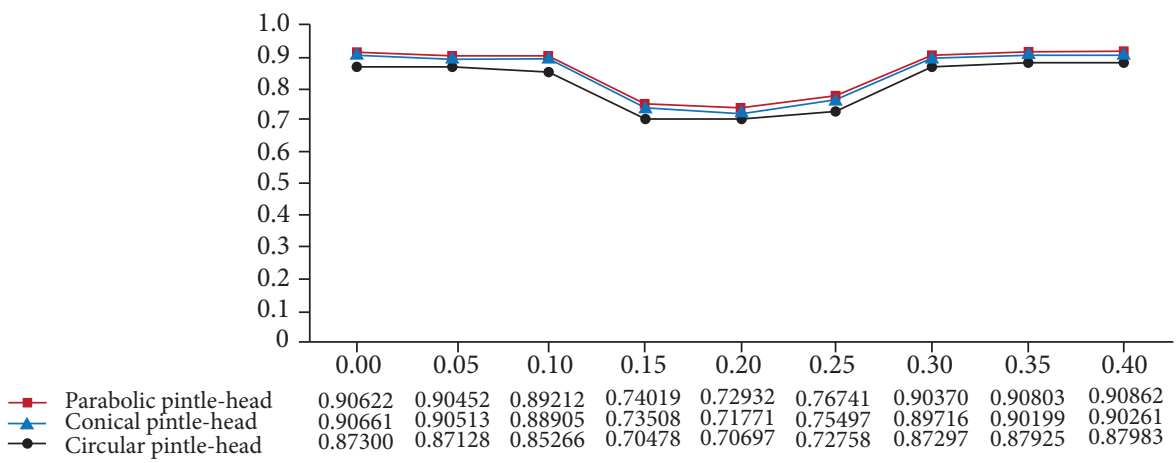

Figure 6. Total pressure recovery coefficient values of pintle models. 


\section{MACH NUMBER}

Figure 7 illustrates the Mach number contour of three different pintle head models, pintle movement from the flow time duration of $0.05 \mathrm{~s}$ to $0.2 \mathrm{~s}$. As the pintle starts to insert inside the nozzle throat area the flow is choked by the pintle and the sonic line starts to move upstream from the flow time of $0.10 \mathrm{~s}$ in all the models. In Fig. 7 we can see that the sonic line seems to be more steady and prominent once the pintle entered the nozzle throat. When the pintle begins to enter the expansion section of the nozzle after the flow time of $0.15 \mathrm{~s}$, the compression shock wave starts to generate from the slope of the pintle head and gets reflected in the nozzle wall, as illustrated in Figs. 7 and 8. Supersonic flow turning at the pintle tip generates the compression wave and trailing shock wave where a closed wake recirculation or tip separation can be observed in the downstream of the sonic line (Fig. 8).

As seen in Fig. 7, the flow between the pintle tip and the nozzle inlet is subsonic when pintle is inside the combustion surface area. Once the pintle is inserted in the nozzle throat it reduces the flow passage, which accelerates the downstream flow of the sonic line and forms the tip shocks extending from the rearward of the pintle tip. It is observed that greater the pintle tip angle,

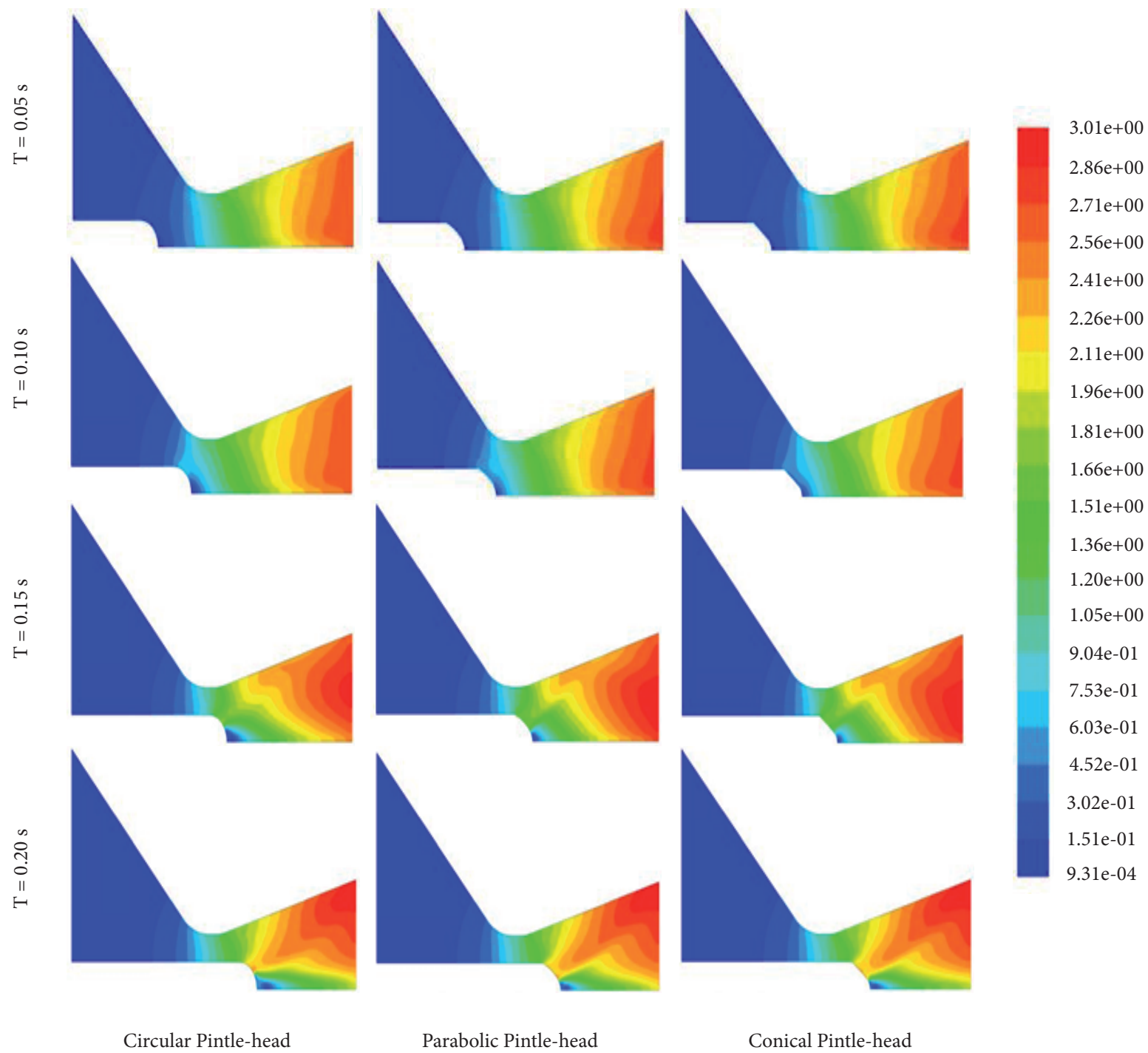

Figure 7. Mach contours of three different pintle models from the flow time of $0.05 \mathrm{~s}$ to $0.2 \mathrm{~s}$. 
the stronger the lip shock, as shown in Fig. 8. The occurrence of the stronger shock wave is shifted upstream as the tip angle approaches to the baseline value.

Figure 9 illustrates the obtained Mach number simulation data of three different pintle head models. Mach number, constant and steady at the beginning phase of pintle moving inside the combustion surface area, starts to increase rapidly as the pintle entered the nozzle throat from the flow time duration of $0.10 \mathrm{~s}$ to $0.15 \mathrm{~s}$. Afterward it rapidly decreases as the pintle reached the expansion section of the nozzle. When the pintle began to reciprocate from the nozzle outlet to the nozzle throat from the flow time duration of $0.2 \mathrm{~s}$ to $0.26 \mathrm{~s}$, Mach number starts to increase rapidly with the maximum value, rapidly decreasing afterward as the pintle retracted back from the nozzle throat to its initial position in all models. The changes in the geometrical throat area by the pintle and dependency of the flow structure on the pintle shape and location significantly change the performance of Mach number. It has been observed that the Mach number is maximum when pintle is reciprocating back to the nozzle throat area from the nozzle outlet, and minimum when pintle reaches the expansion section of the nozzle. Among three different models, parabolic pintle head model has the maximum value of Mach number, and circular pintle head model has the minimum value. It can analyze that the performance of Mach number varies according to the pintle shape and location.

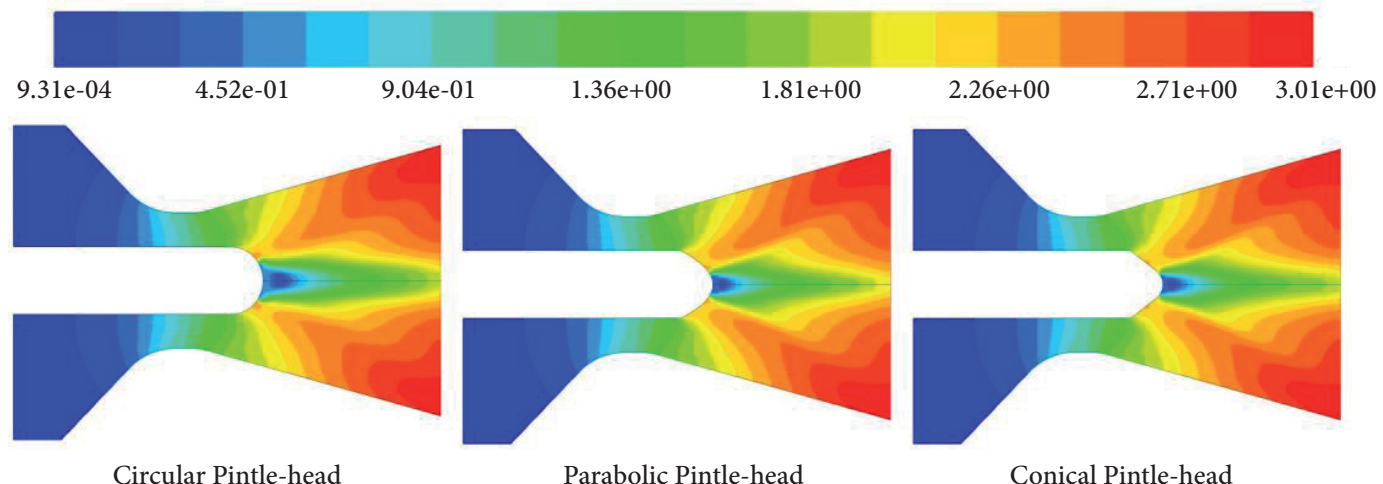

Figure 8. Three different pintle models Mach contours at the flow time of $0.2 \mathrm{s.}$

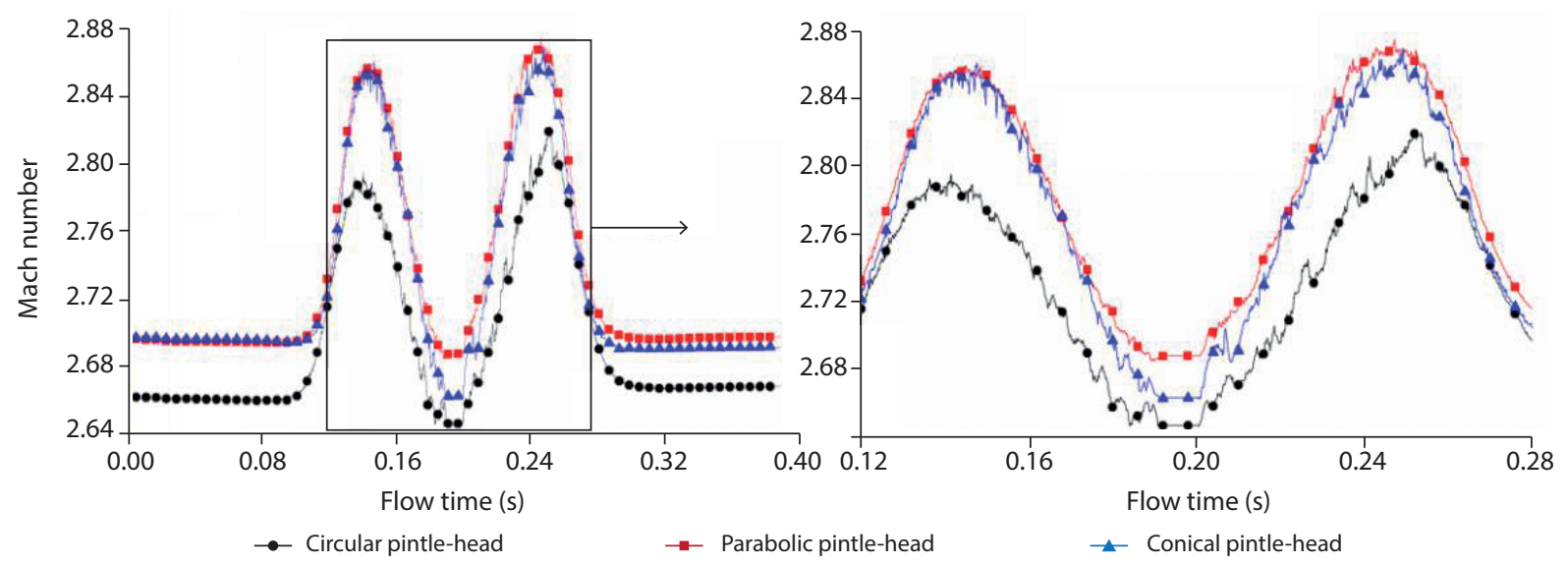

Figure 9. (a) Mach number simulation data of three different models at the outlet of nozzle; (b) Magnified display from the flow time of $0.12-0.28$ s

\section{TOTAL MASS FLOW RATE}

The chamber pressure is a function of the mass-burning rate of the propellants that depends on the propellant density, burning area, coefficient, and exponent of the burn rate. The mass flow of the burning surface of the solid propellant is modeled with a user-defined function to define the mass flux of the end-burning propellant, as follows (Eq. 11): 


$$
\frac{\dot{m}}{A}=r_{p} \dot{r}=r_{p} a p^{n}
$$

where $\rho_{p}$ represents the propellant density of $1660 \mathrm{~kg} / \mathrm{m}^{3} ; \dot{r}$ is the burning rate of the propellant; $a$ is the coefficient value of $1.018982 \times 10^{-4}$; and $n$ is the exponent of the burning rate of the propellant, which is 0.3309 . The combustion boundary moving with the burning rate is neglected.

Figure 10 illustrates the inlet and outlet mass-flow rate of three different pintle head models. The obtained simulation data showed that circular pintle head model reacted fast and had the maximum value of total mass-flow rate compared to other models. It has observed that the simulation data of both conical and parabolic pintle head models have the same aligning values of inlet and outlet mass-flow rate. The constant and steady mass-flow rate of all models in the beginning stage of pintle moving to the front edge of the nozzle throat started changing synchronously for both inlet and outlet when the pintle started to enter the convergence section of the nozzle throat area after the flow time of $0.11 \mathrm{~s}$ in all models. The inlet mass flow rate is maximum when the pintle reaches the expansion section of the nozzle throat or the nozzle from the flow time duration of $0.2-0.25 \mathrm{~s}$. Then inlet mass-flow rate gradually decreases when the pintle is retracting back towards its initial position after the flow time of $0.25 \mathrm{~s}$. But it is observed that outlet mass flow rate decreased when the pintle started to enter the nozzle throat area and rapidly increased afterward as the pintle entered the nozzle throat. An instantaneous increase has been observed in the outlet mass flow rate from the flow time duration of $0.23 \mathrm{~s}$ to $0.28 \mathrm{~s}$ when the pintle retracted back from the nozzle outlet to the nozzle throat. At the same flow time, the inlet mass flow rate rapidly decreased and outlet mass flow rate achieved the maximum value and rapidly decrease afterward as the pintle retract back to its initial position from the nozzle throat. From the obtained data of inlet mass-flow rate and pressure, we can analyze that the mass flow rate is directly proportional to the combustion chamber pressure, which has the similar tendency of reaction with all pintle models at the same period of flow time. The shock formed from the pintle causes a separation flow at the nozzle wall. These flow patterns lead to a variation of the mass flow rate at the nozzle exit. Therefore, as the pintle moves toward the nozzle exit, the mass flow rate decreases and the nozzle flow becomes over expanded.

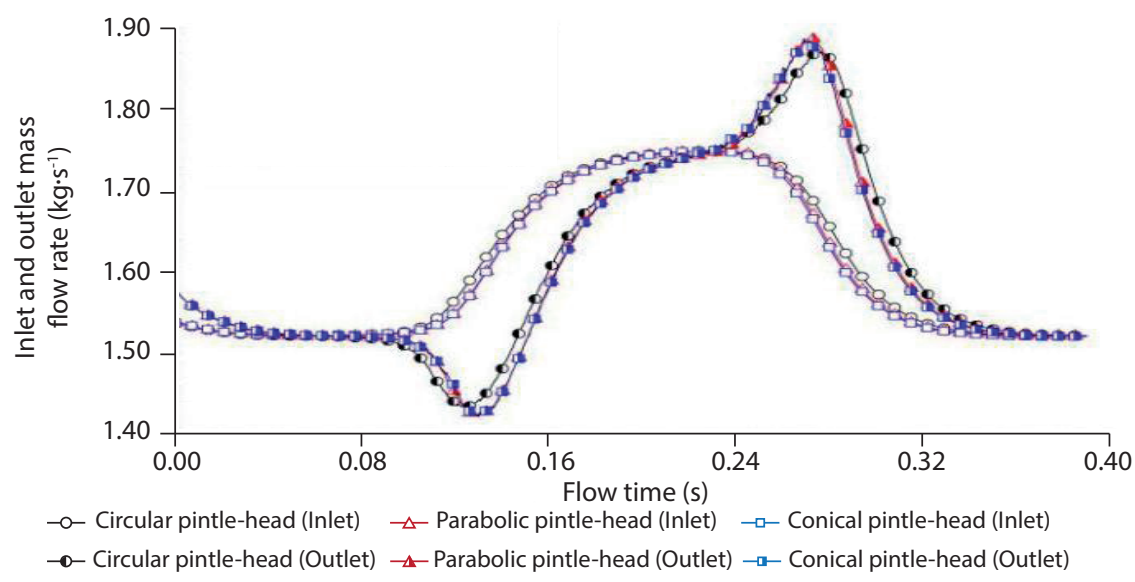

Figure 10. Inlet and Outlet mass flow rate of three different pintle models.

\section{TOTAL THRUST}

The total thrust represents the force in $\mathrm{x}$-coordinate and can be obtained with the following equation:

$$
F=\dot{m} V_{e}+\left(p_{e}-p_{a}\right) A_{e}
$$

where $F$ is the total net thrust; $\dot{m}$ is the mass flow rate; $V_{e}$ is the exit velocity; $p_{e}$ is the total combustion chamber pressure; $p_{a}$ is the ambient pressure; and $A_{e}$ is the nozzle exit area. 
The net thrust of different pintle head model with the flow time is shown in Fig. 11. The parabolic shape pintle has the maximum net thrust $(\sim 41250 \mathrm{~N})$, and the circular shape pintle has the minimum thrust $(\sim 38750 \mathrm{~N})$ among three different pintle models used in this study. According to the thrust effect, parabolic pintle has the maximum value of thrust and the greatest total pressure recovery coefficient among all the pintle-head models. Hence, it was selected as the base model to investigate the further dynamic characteristics of the pintle movement effects on the thrust regulation in this research.

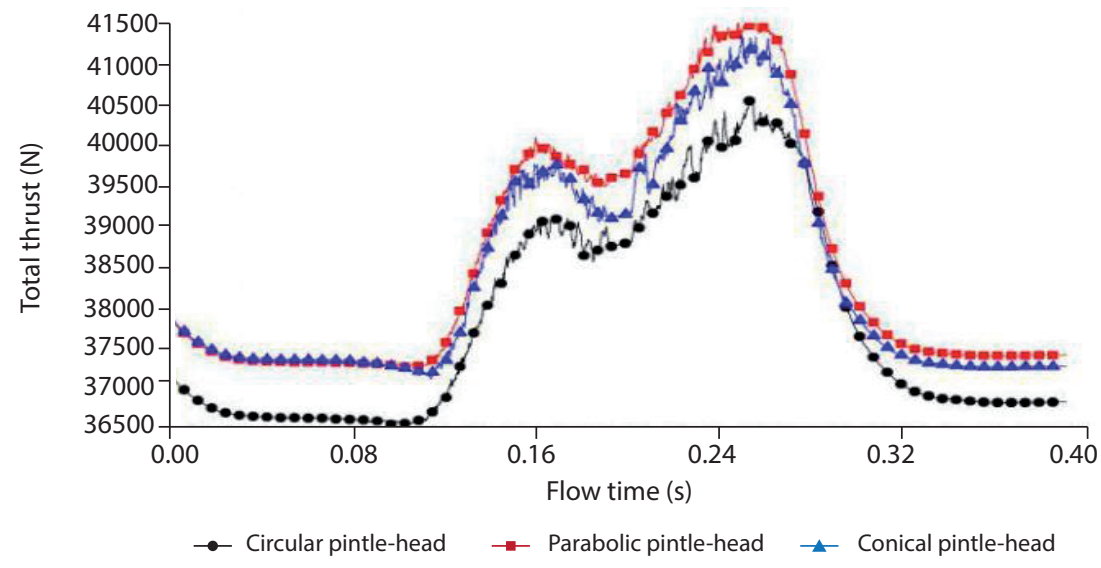

Figure 11. Total thrust of three different pintle models.

Figure 12 illustrates the comparison data of parabolic pintle-head model Mach number, mass-flow rate and total thrust. As the pintle began to enter the nozzle throat after the flow time of $0.10 \mathrm{~s}$, the drastic changes started to occur in the massflow rate, Mach number and total thrust. The inlet mass-flow rate, Mach number, and total thrust increased rapidly as the pintle started to enter the nozzle throat. At the same period of flow time, the outlet mass flow rate declined for a period and increased subsequently from the flow time duration of $0.13 \mathrm{~s}$. Mach number and total thrust increased at the initial stage of pintle entering to the nozzle throat but declined later on as the pintle reached to the expansion section of the nozzle from the flow time duration of $0.15 \mathrm{~s}$ to $0.19 \mathrm{~s}$. This phenomenon is resulted from the occurrence of flow separation and changes inside the nozzle throat area by the pintle while entering through the nozzle throat. The supersonic flow behind the nozzle throat precipitated the occurrence and detachment of the shock wave appearance with the complex flow pattern structure, which mainly depends on the pintle shape and location. On the other hand, due to the changes in the area of nozzle throat by the pintle, the inlet mass-flow rate keeps increasing. It remained constant for a period with the maximum value from the flow time duration of pintle starting to enter the nozzle throat and reaching to the expansion section of the nozzle, subsequently decreasing as the pintle retracted back to its initial stage.

In Fig. 12 we can see that, when the pintle began to reciprocate towards its initial stage after the flow time duration of $0.2 \mathrm{~s}$, Mach number and total thrust increased along with increasing outlet mass-flow rate, where inlet mass flow rate remained constant for a while with the approximate maximum value of $1.749 \mathrm{~kg} / \mathrm{s}$. As the pintle reached the nozzle throat while retracting back towards its initial position after the flow time of $0.23 \mathrm{~s}$, the inlet mass flow rate started to decrease and an instantaneous increase in Mach number, total thrust and outlet mass-flow rate was observed, which sequentially reached to its maximum value in different time span from each other. An instantaneous increase in Mach number and total thrust in the difference of a specific time span is due to the phase lag of the chamber pressure, which requires a certain time to travel from the combustion chamber to the nozzle throat outlet.

As one can see in Fig. 12, outlet mass-flow rate reached to its maximum value at the flow time duration of $0.29 \mathrm{~s}$, when the total thrust and Mach number already decreased. The phase variation between the thrust and mass-flow rate occurred due to the time elapsed in the reflection of the wave from the chamber to the nozzle throat and decreases sharply afterwards, as the pintle retracted from the nozzle throat to its initial stage due to changes occurred by the pintle in the area of the nozzle throat. It was 
observed that the thrust is maximum when the pintle is retracting back from the nozzle outlet to the nozzle throat than the pintle entering the nozzle throat from its initial position.

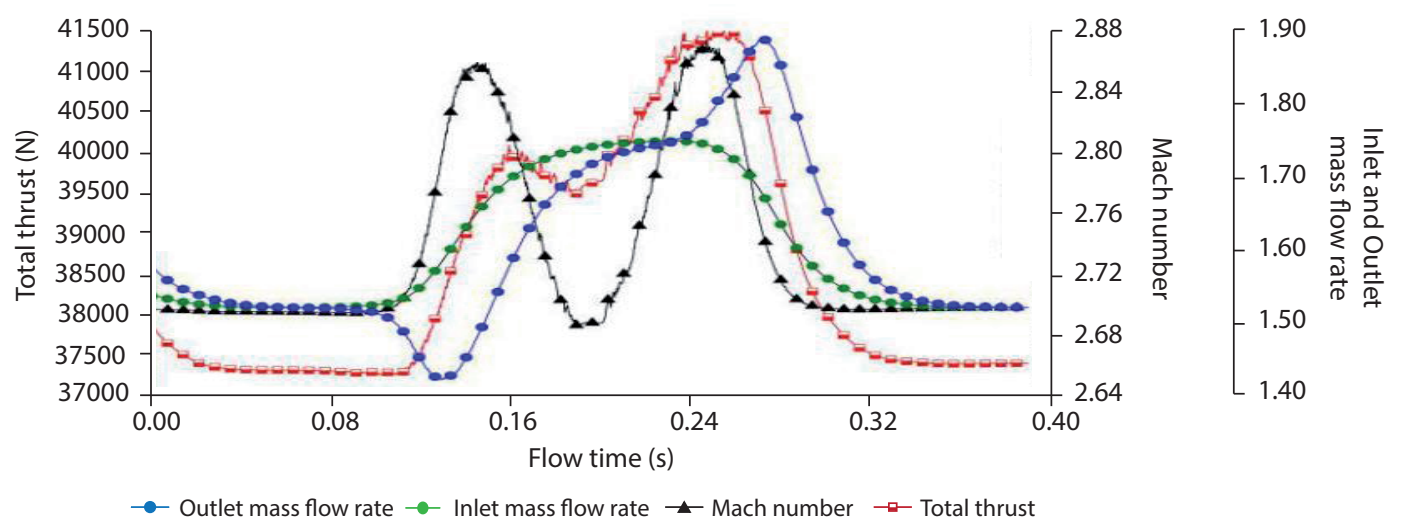

Figure 12. Simulation data of parabolic pintle head Mach number, mass flow rate and total thrust.

\section{CONCLUSION}

The following conclusions had been deduced and summarized by the numerical study performed in this research to investigate the response characteristic of three different pintle head models on thrust regulation effect of SRM.

- According to the analysis of total pressure response time, we can conclude that circular pintle responded faster than the other models. According to the thrust effect, parabolic pintle yields the maximum value of thrust and greater total pressure recovery coefficient, compared to the other models.

- As pintle starts to enter the nozzle throat, the changes in the area of nozzle throat by the pintle-head causes the sudden high spike of the pressure changes inside the combustion chamber. Different pintle head shapes have different impacts on the sudden rise and fall of total pressure inside the combustion chamber.

- The smaller nozzle throat area, which has been blocked by the pintle, substantially increases the thrust for which increase in chamber pressure is responsible. The inlet mass flow rate is directly proportional to the pressure.

- Total pressure recovery coefficient decreases with the increasing amount of total pressure, and conversely increases as total pressure decreases. The supersonic flow behind the nozzle throat precipitated the occurrence and separation of the shock wave to appear with complex flow pattern structure, which mainly depends on the pintle shape and location. It has observed that greater the pintle tip angle, the stronger the lip shock. The obtained result suggests chamber pressure is the dominant factor determining the thrust in SRM, where shock structure and shock train are dependent on the pintle shape.

- It was observed that the thrust is greater when the pintle is retracting back from the nozzle outlet to the nozzle throat than when the pintle entering the nozzle throat from its initial position. It is due to the phase lag of the chamber pressure, which takes a specific time to travel from combustion chamber to the nozzle outlet.

\section{AUTHOR'S CONTRIBUTION}

Conceptualization, Xu YH; Methodology, Xu YH, Sapkota J and Sun HJ; Investigation, Sapkota J, Xu YH and Sun HJ; Writing - Original Draft, Sapkota J; Writing - Review and Editing, Xu YH, Sapkota J and Sun HJ; Funding Acquisition, Xu YH; Resources, $\mathrm{Xu}$ YH and Sun HJ; Supervision, Xu YH. 


\section{FUNDING}

National Natural Science Foundation of China [https://doi.org/10.13039/501100001809]

Grant no. 51666012

\section{REFERENCES}

Bergmans JL, Salvo RD (2003) Solid rocket motor control: theoretical motivation and experimental demonstration. Presented at: 39th IAAA/ASME/SAE/ASEE Joint Propulsion Conference and Exhibit; Huntsville, USA. https://doi.org/10.2514/6.2003-4968

Burroughs S (2001) Status of army pintle technology for controllable thrust propulsion. Presented at: 37th Joint Propulsion Conference and Exhibit; Salt Lake City, USA. https://doi.org/10.2514/6.2001-3598

Coon J, Yasuhara W (1993) Solid propulsion approaches for terminal steering. 2nd AIAA SDIO Interceptor Technology Conference. Presented at: Annual Interceptor Technology Conference; Albuquerque, USA. https://doi.org/10.2514/6.1993-2641

Dahl H, Jones B (1996) Demonstration of solid propellant pulse motor technologies. Presented at: 32nd Joint Propulsion Conference and Exhibit; Lake Buena Vista; USA. https://doi.org/10.2514/6.1996-3157

Davis CA, Gerards AB (2OO3) Variable thrust solid propulsion control using labview. Presented at: 39th IAAA/ASME/SAE/ASEE Joint Propulsion Conference and Exhibit; Huntsville, USA. https://doi.org/10.2514/6.2003-5241

Lee JY (2012) A Study on the Static and Dynamic Characteristics of Pintle- Perturbed Conical Nozzle Flows (PhD Dissertation). Seoul: Yonsei University.

Heo JY, Jeong KY, Sung HG (2013) Numerical study on dynamic characteristics of pintle nozzle for variant thrust: part 3. Presented at: 39th Korean Society of Propulsion Engineers Spring Conference; Daejeon, Korea.

Lee JH, Park BH, Yoon W (2013) Parametric investigation of the pintle-perturbed conical nozzle flows. Aerospace Science and Technology 26(1):268-279. https://doi.org/10.1016/j.ast.2012.05.005

Li J, Wang ZL, Zheng K, Li J (2009) Numerical analysis on dynamic response characteristics of pintle-controlled solid rocket motor. Journal of Solid Rocket Technology 32(1):48-52

Ostrander MJ, Bergmans JL, Thomas ME, Burroughs SL (2000) Pintle motor challenges for tactical missiles. Presented at: 36th IAAA/ ASME/SAE/ASEE Joint Propulsion Conference and Exhibit; Las Vegas, USA. https://doi.org/10.2514/6.2000-3310

Rock SG, Habchi SD, Marquette TJ (1997) Numerical simulation of controllable propulsion for advanced escape systems. Presented at: 15th Applied Aerodynamics Conference; Atlanta, USA. https://doi.org/10.2514/6.1997-2254 